Supporting Information (SI)

\title{
Understanding the Dissolution and Phase Transformation Mechanisms in Aqueous $\mathrm{Zn} / \alpha-\mathrm{V}_{2} \mathrm{O}_{5}$ Batteries
}

\author{
Kaiyue Zhu, Tao Wu* and Kevin Huang* \\ Department of Mechanical Engineering, University of South Carolina, Columbia, SC29201
}



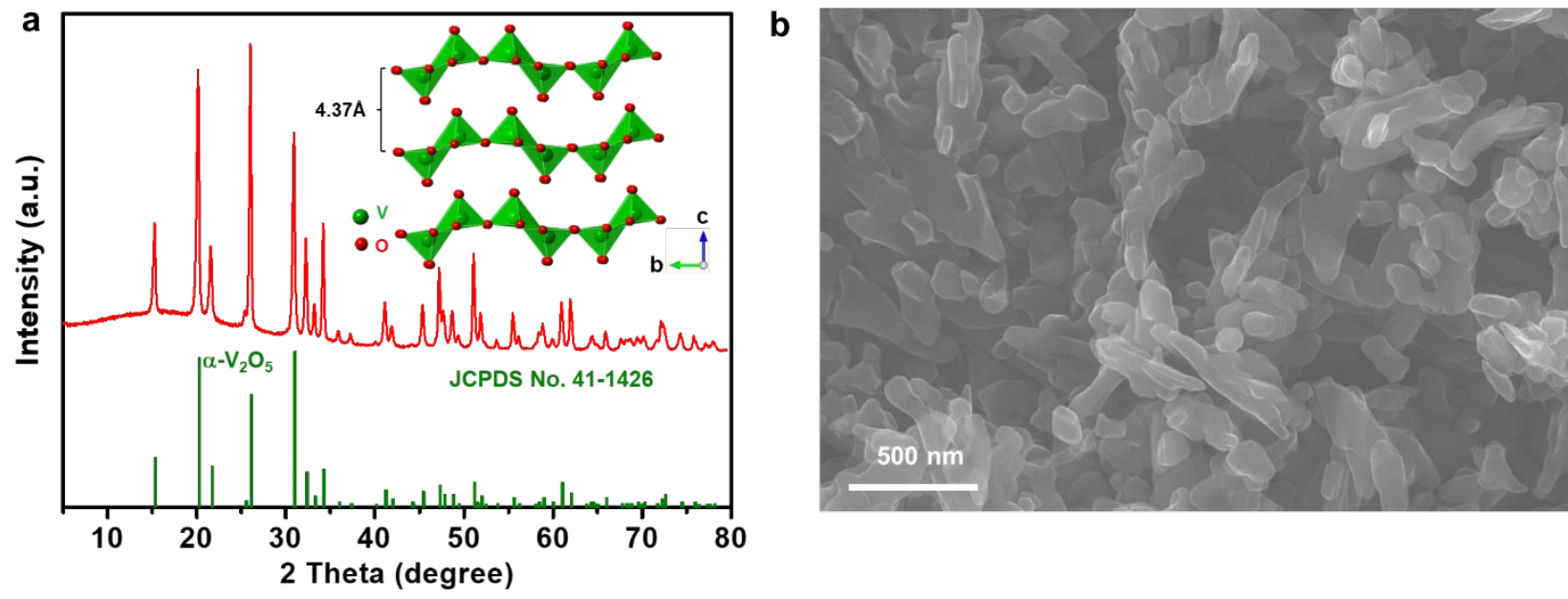

Figure S1 (a) XRD patterns and (b) SEM image of as-prepared $\alpha-\mathrm{V}_{2} \mathrm{O}_{5}$ powder. Inset in Figure $\mathbf{a}$ is a crystal structure of the orthorhombic $\alpha-\mathrm{V}_{2} \mathrm{O}_{5}$.
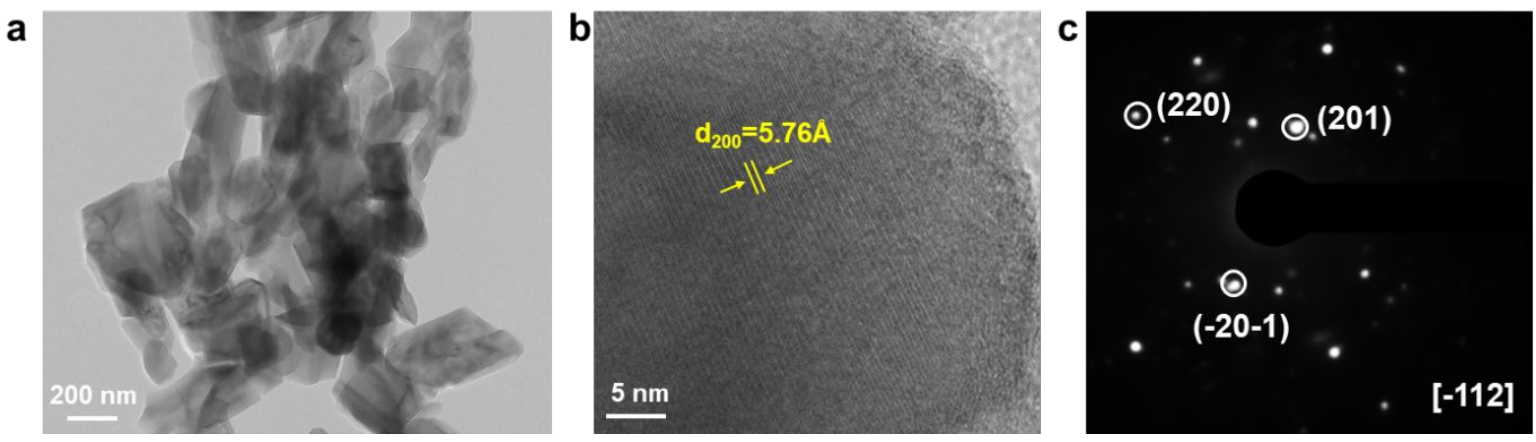

Figure S2 (a) TEM image, (b) HRTEM, and (c) SAED image of the as-prepared $\alpha-\mathrm{V}_{2} \mathrm{O}_{5}$ powder. 


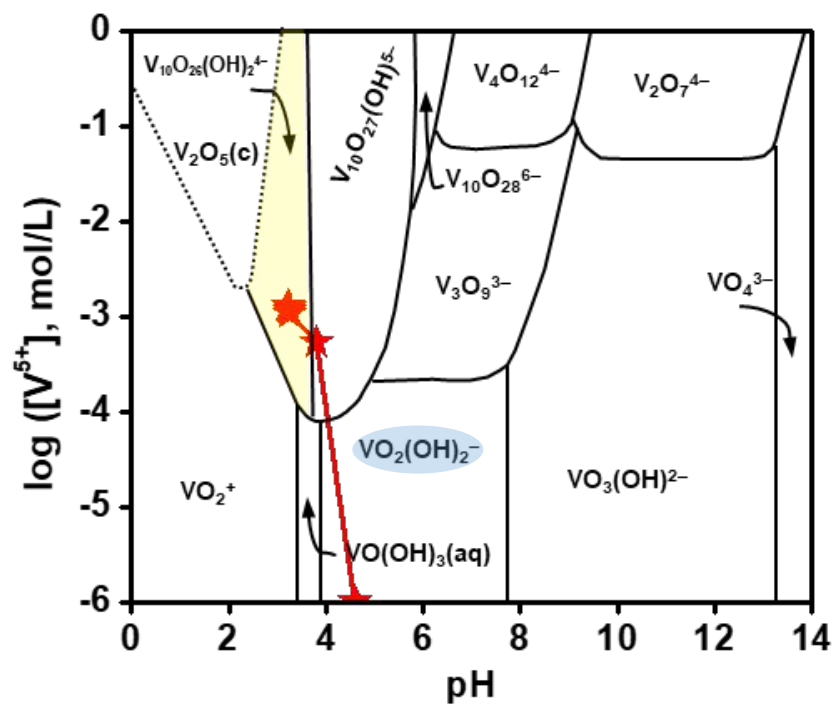

Figure S3 Predominant $\mathrm{V}^{5+}$ species in aqueous solutions at $25{ }^{\circ} \mathrm{C}$ as a function of vanadium concentration $\left(\left[\mathrm{V}^{5+}\right]\right)$ and $\mathrm{pH}$, according to ref $1 .{ }^{1}$ The red stars in yellow area represent the $\mathrm{V}$ content and $\mathrm{pH}$ value in $\mathrm{ZnSO}_{4}$ solution after soaking $\alpha-\mathrm{V}_{2} \mathrm{O}_{5}$ electrode over time.

a

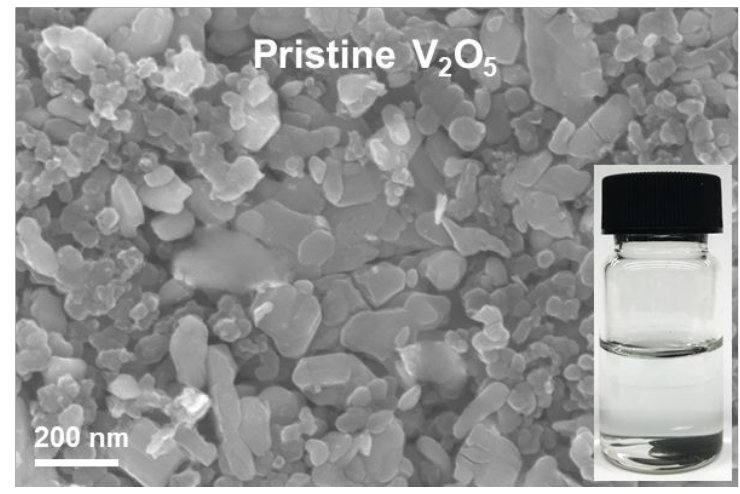

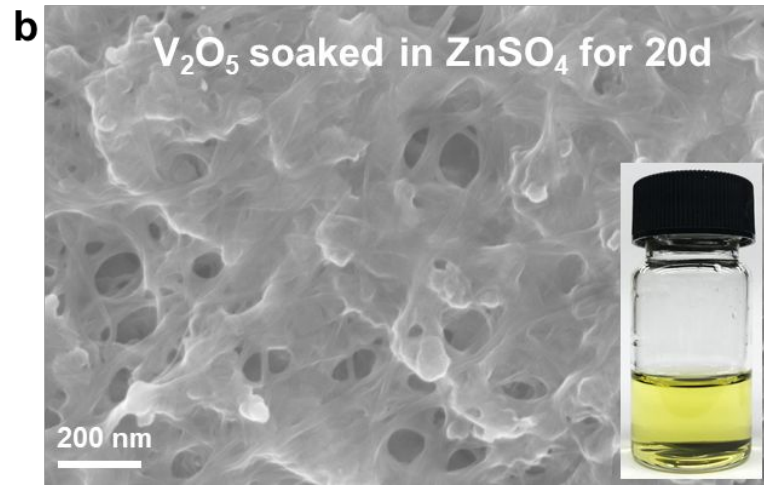

Figure S4 SEM images of $\alpha-\mathrm{V}_{2} \mathrm{O}_{5}$ electrode before (a) and after (b) soaking in $2 \mathrm{M} \mathrm{ZnSO} 4$ electrolyte for 20 days, respectively. The insets are the digital image of corresponding $\alpha$ $\mathrm{V}_{2} \mathrm{O}_{5} / \mathrm{ZnSO}_{4}$ systems at different periods. 

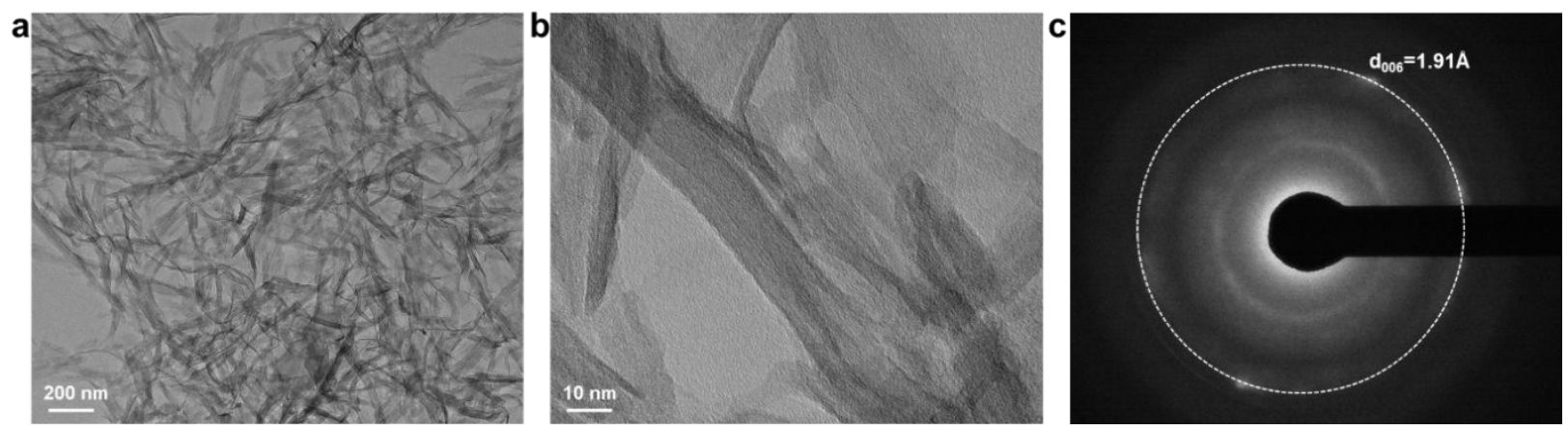

Figure S5 (a) TEM images, (b) HRTEM, and (c) SAED image of $\mathrm{H}_{-}-\mathrm{V}_{2} \mathrm{O}_{5}$ obtained by soaking $\alpha$ $\mathrm{V}_{2} \mathrm{O}_{5}$ powders in $2 \mathrm{M} \mathrm{ZnSO}_{4}$ for 20 days.
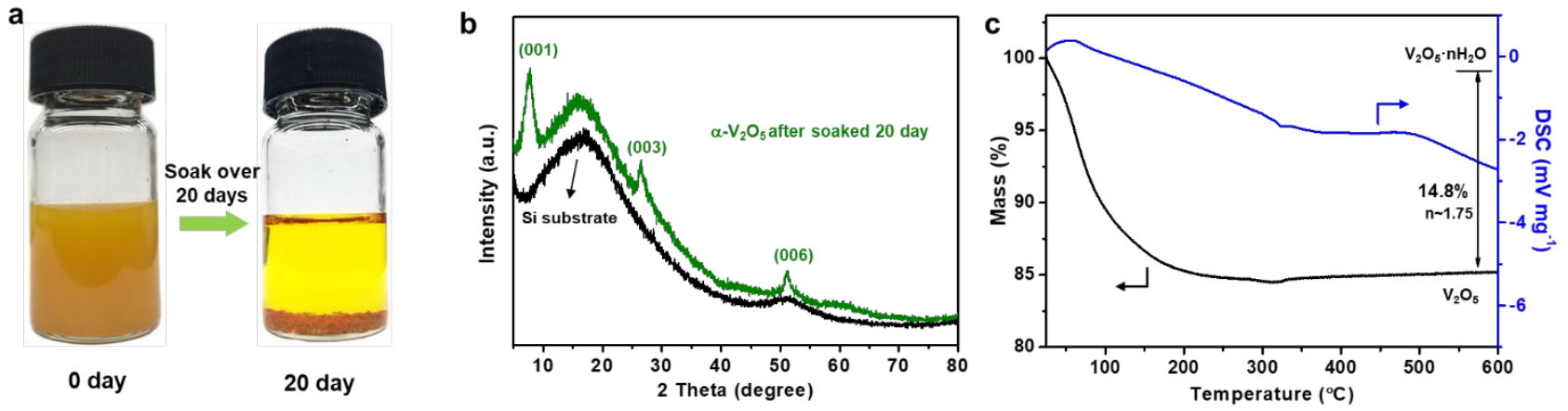

Figure S6 (a) The digital images of as-prepared $\alpha-\mathrm{V}_{2} \mathrm{O}_{5}$ powders $(0.5 \mathrm{~g})$ soaked in $10 \mathrm{~mL} 2 \mathrm{M}$ $\mathrm{ZnSO}_{4}$ for 0 day and 20 days, respectively; (b) XRD pattern; (c)TG analysis of $\alpha-\mathrm{V}_{2} \mathrm{O}_{5}$ powders soaked in $10 \mathrm{~mL} \mathrm{ZnSO}_{4}$ for 20 days. The black line in (b) is the $\mathrm{Si}$ substrate used in XRD to support powders. 


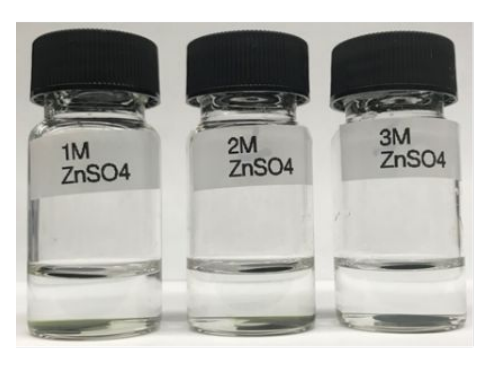

0 day

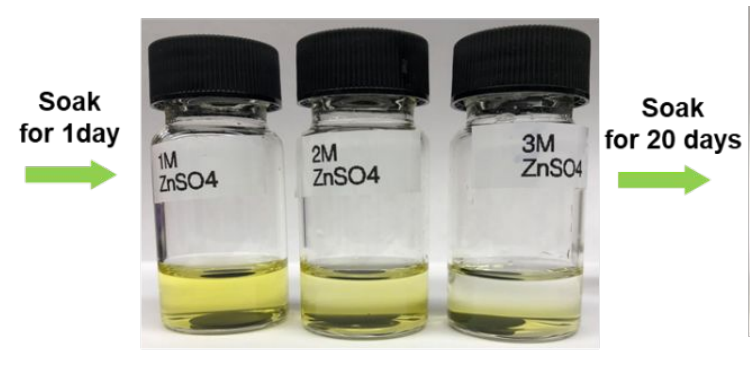

1 day

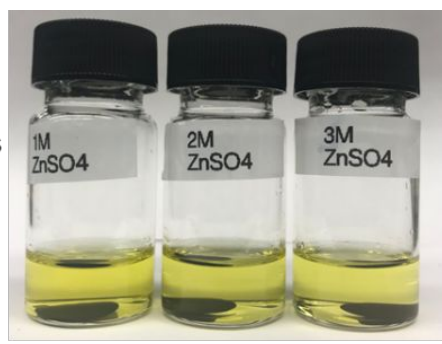

20 days

Figure S7 Digital images of as-prepared $\alpha-\mathrm{V}_{2} \mathrm{O}_{5}$ electrode (active mass, $1.5 \mathrm{~g}$ ) soaked in $\mathrm{ZnSO}_{4}$ electrolyte $(5 \mathrm{~mL})$ with concentrations of 1,2 , and $3 \mathrm{M}$ for 0,1 and 20 days, respectively. After soaking for 20 days, the $\mathrm{pH}$ value of 1,2 and $3 \mathrm{M} \mathrm{ZnSO}_{4}$ electrolyte decreased from 4.89 to 3.61 , 4.56 to 3.51 , and 4.23 to 3.36 , respectively.
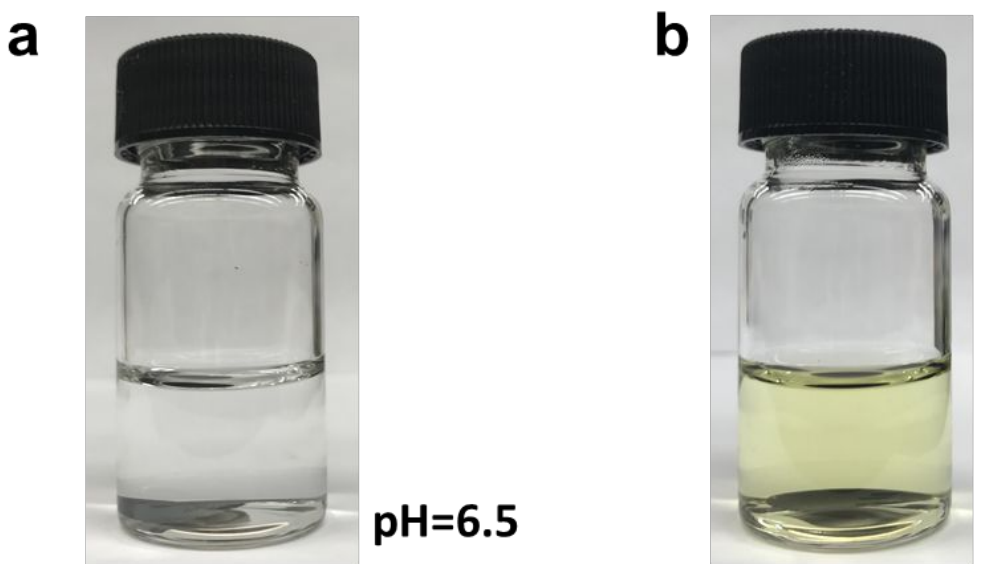

$\mathrm{pH}=4.3$

Figure S8 Digital images of $\alpha-\mathrm{V}_{2} \mathrm{O}_{5}$ electrode (active mass, $1.6 \mathrm{mg}$ ) soaked in $8 \mathrm{~mL} \mathrm{H}_{2} \mathrm{O}$ for 0 and 1 day, respectively. After soaking $\alpha-\mathrm{V}_{2} \mathrm{O}_{5}$ electrode, the $\mathrm{pH}$ value of solution decreased from 6.5 to 4.3 . 

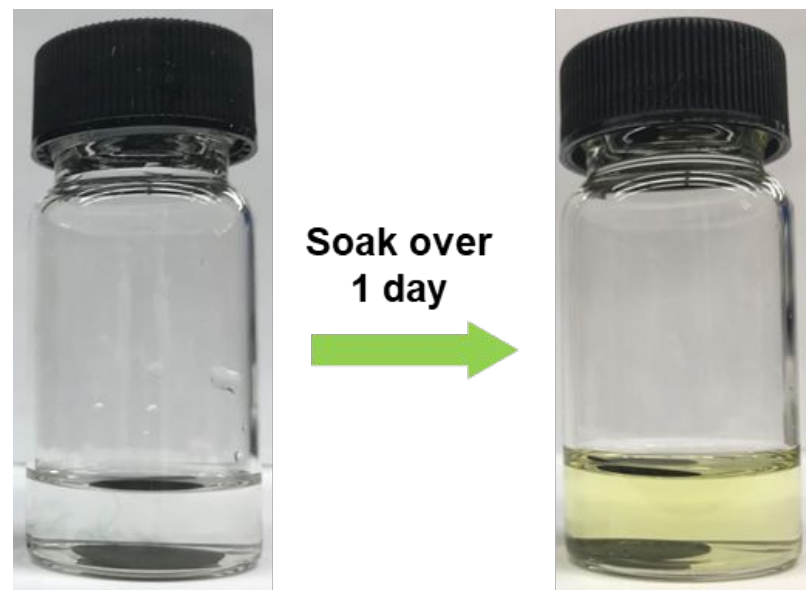

Figure S9 The optical image of $\alpha-\mathrm{V}_{2} \mathrm{O}_{5}$ in $2 \mathrm{M} \mathrm{Zn}\left(\mathrm{NO}_{3}\right)_{2}$ after 1 day.
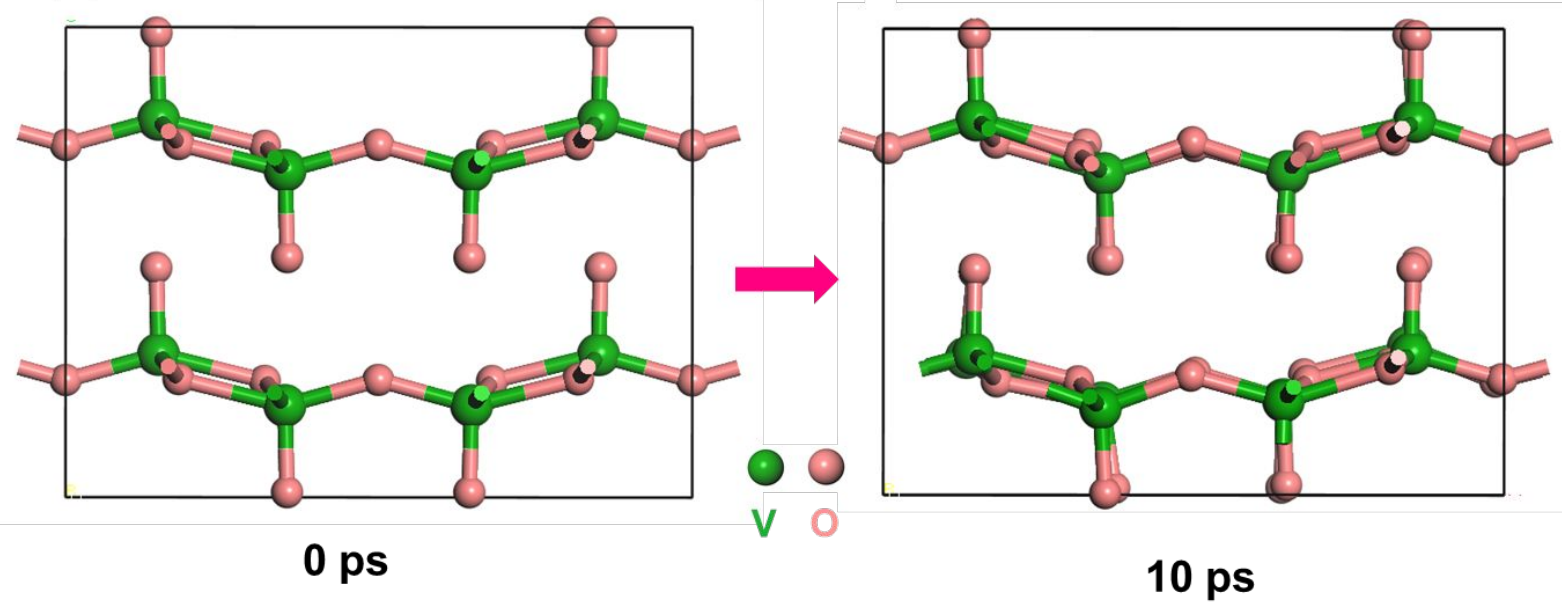

Figure S10 Snapshots of $\alpha-\mathrm{V}_{2} \mathrm{O}_{5}$ in an atmosphere without water at 0 and $10 \mathrm{ps}$, respectively. 

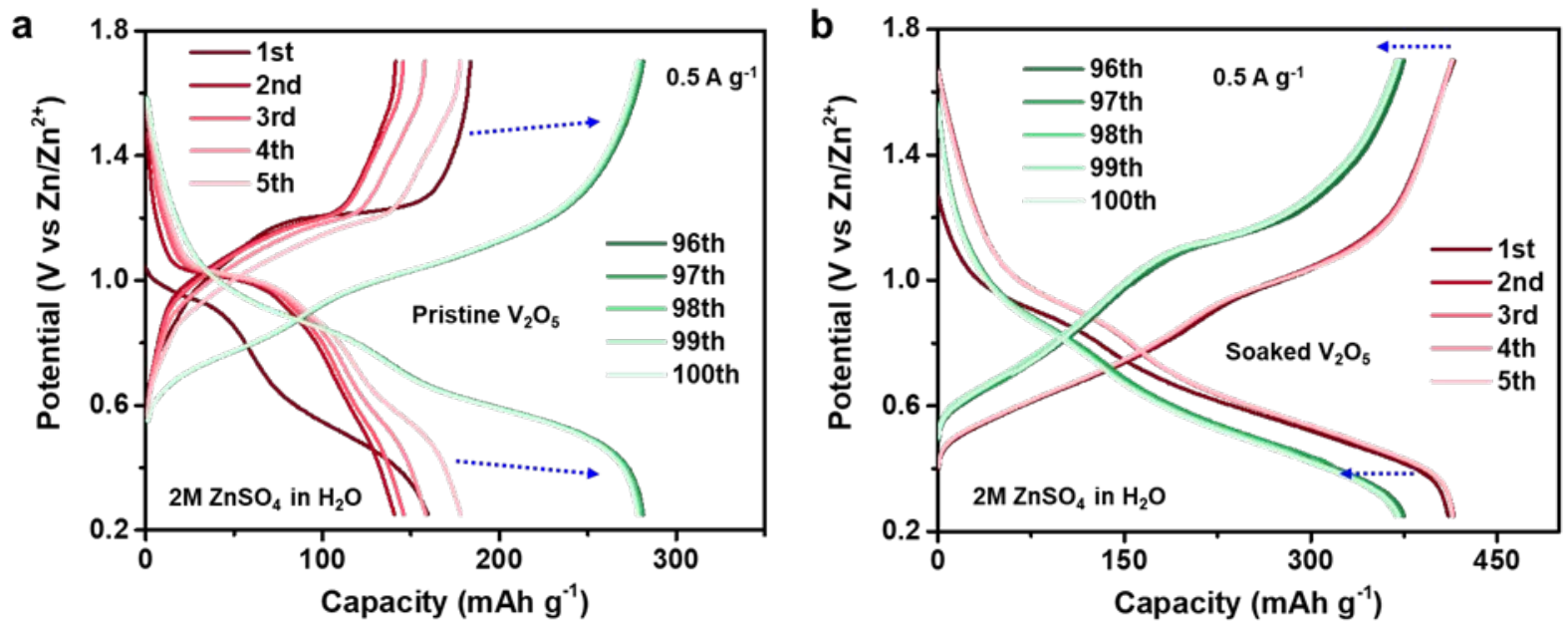

Figure S11 The galvanostatic discharge/charge profiles of cycle 1st-5th and 96th -100 th at $0.5 \mathrm{~A}$ $\mathrm{g}^{-1}$ in $2 \mathrm{M} \mathrm{ZnSO}_{4}$ aqueous electrolyte for (a) pristine $\mathrm{V}_{2} \mathrm{O}_{5}$ and (b) soaked $\mathrm{V}_{2} \mathrm{O}_{5}$ cathodes, respectively.
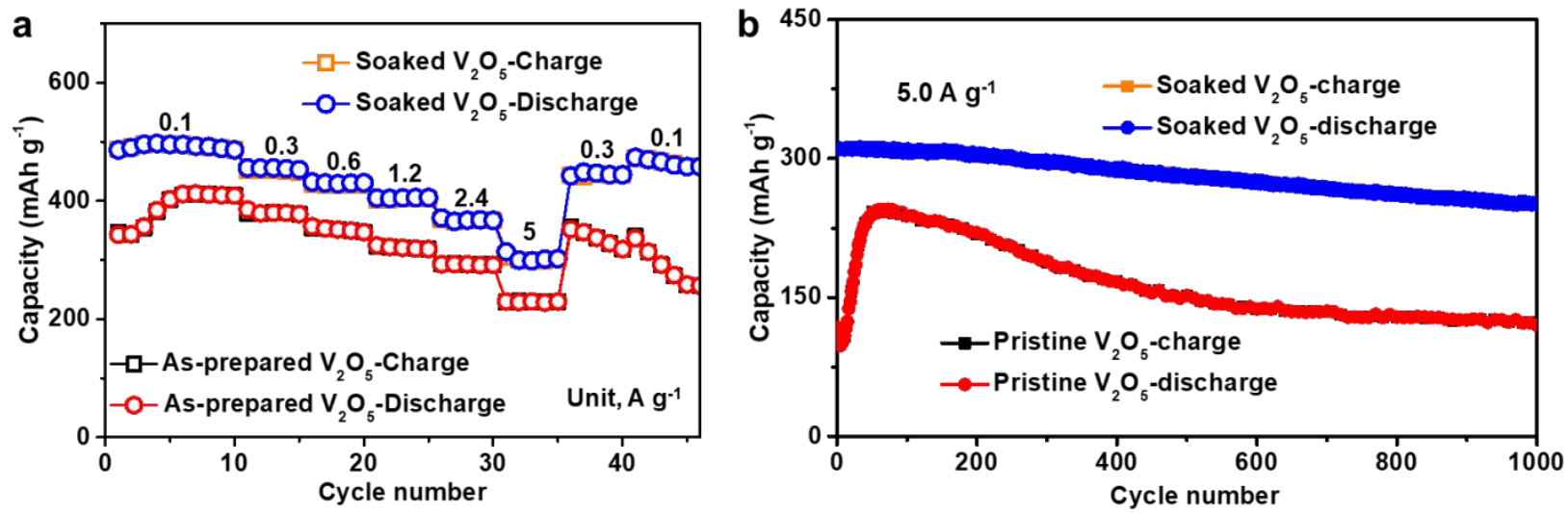

Figure S12 The cycling performance comparison at $0.5 \mathrm{~A} \mathrm{~g}^{-1}$ in aqueous electrolyte of as-prepared $\alpha-\mathrm{V}_{2} \mathrm{O}_{5}$ cathode (as-prepared $\mathrm{V}_{2} \mathrm{O}_{5}$ ) and $\alpha-\mathrm{V}_{2} \mathrm{O}_{5}$ after soaking in $2 \mathrm{M} \mathrm{ZnSO}_{4}$ for 20 days (soaked $\mathrm{V}_{2} \mathrm{O}_{5}$ ): (a) rate performance, cycling performance at $5 \mathrm{~A} \mathrm{~g}^{-1}$. 


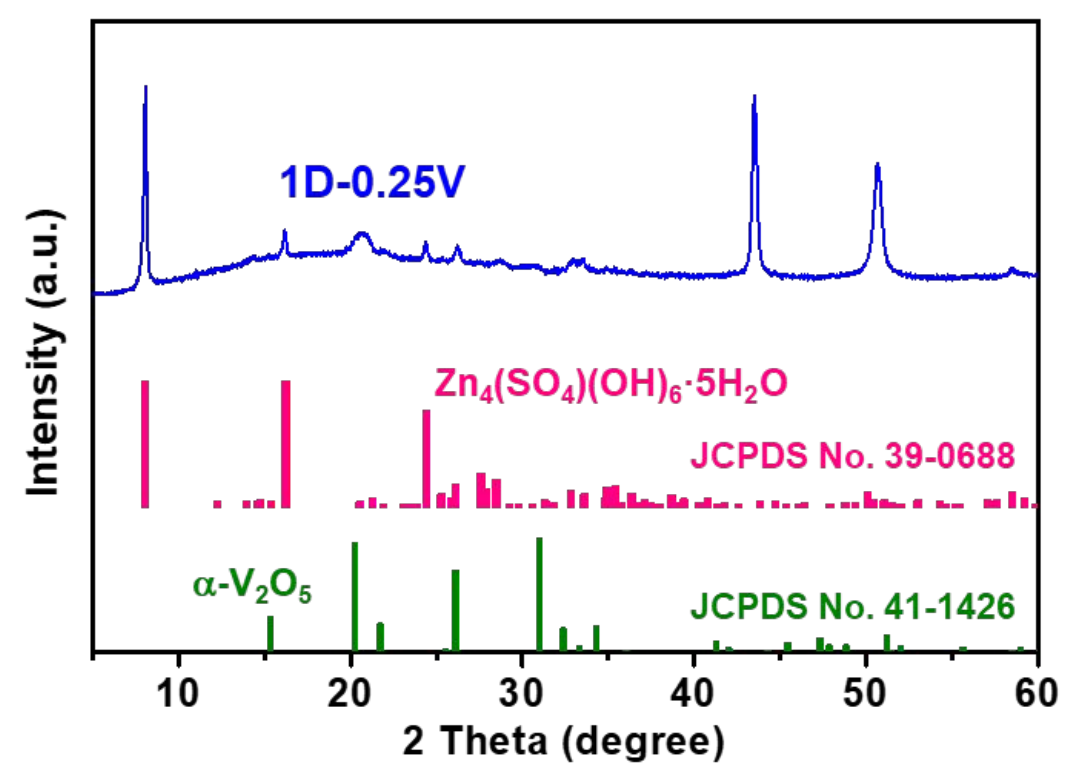

Figure S13 The XRD pattern of $\alpha-\mathrm{V}_{2} \mathrm{O}_{5}$ cathode in $2 \mathrm{M} \mathrm{ZnSO}_{4}$ electrolyte at the discharged state of first cycle (1D-0.25V).
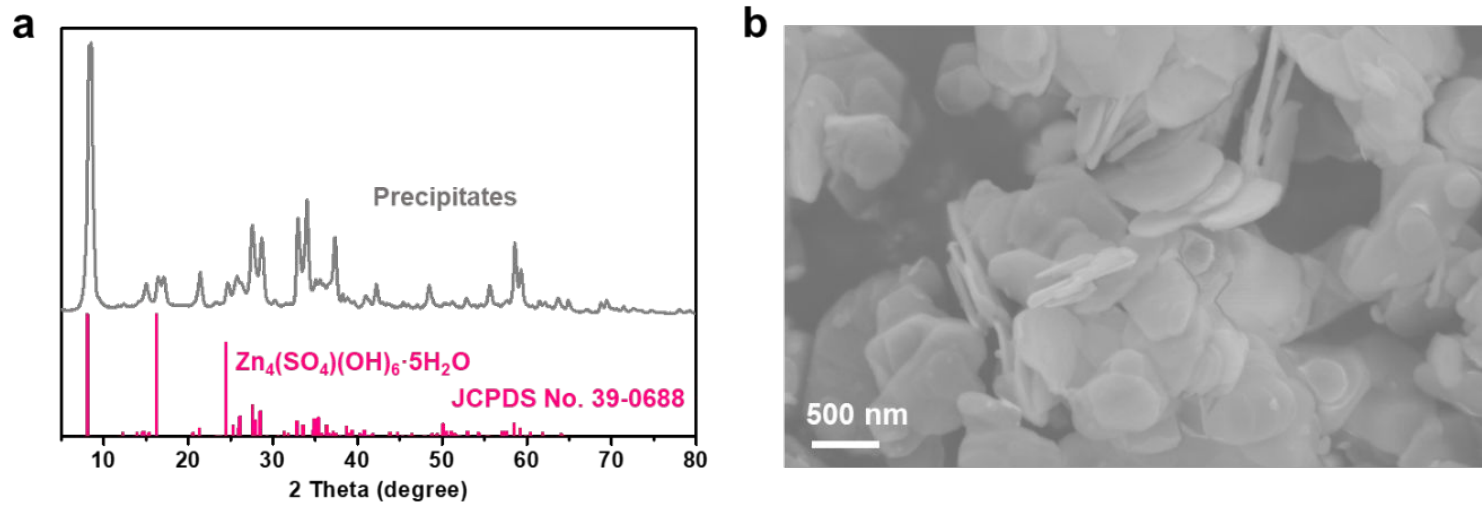

Figure S14 (a) The XRD pattern and (b) SEM image of the precipitates formed by adding $1 \mathrm{M}$ $\mathrm{NaOH}$ solution $(5 \mathrm{~mL})$ into $2 \mathrm{M} \mathrm{ZnSO}_{4}$ solution. $(50 \mathrm{~mL})$ 

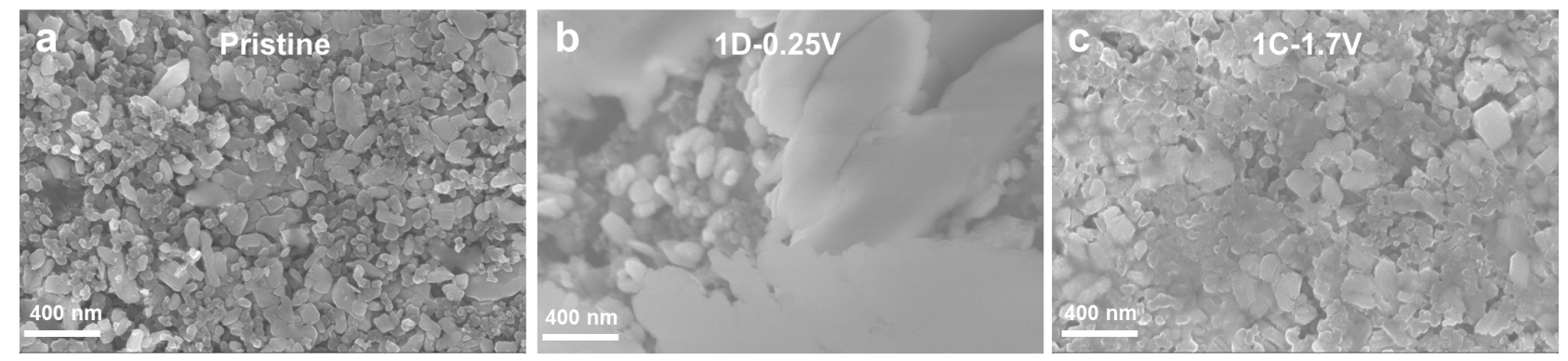

Figure S15 Ex-situ SEM images of the as-prepared $\alpha-\mathrm{V}_{2} \mathrm{O}_{5}$ cathode surface at the pristine state, discharged state (1D-0.25V) and charged state (1C-1.7V) of first cycle in $2 \mathrm{M} \mathrm{ZnSO}_{4}$ electrolyte, respectively.
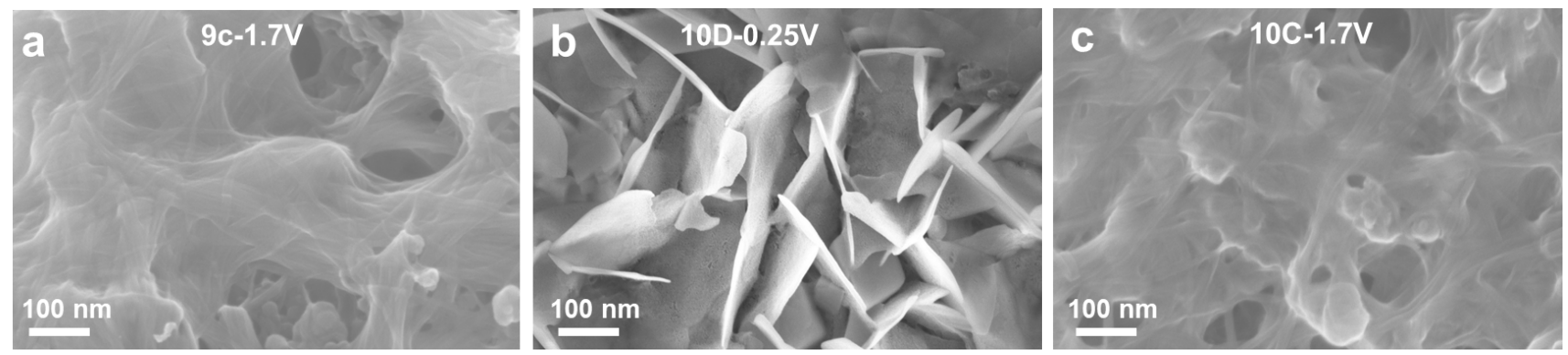

Figure S16 Ex-situ SEM images of $\alpha-\mathrm{V}_{2} \mathrm{O}_{5}$ cathode surface at the 10th cycle, pristine state (9C$1.7 \mathrm{~V})$, discharged state (10D-0.25V) and charged state (10C-1.7V) in $2 \mathrm{M} \mathrm{ZnSO}_{4}$ electrolyte, respectively.
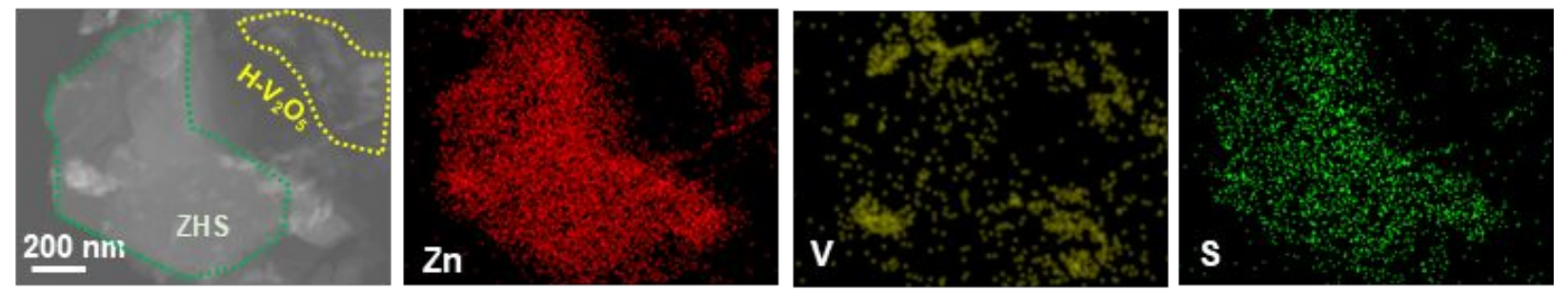

Figure S17 STEM image and Zn, V, and O mappings of $\alpha-\mathrm{V}_{2} \mathrm{O}_{5}$ cathode at discharged state (10D$0.25 \mathrm{~V}$ ) of the $10^{\text {th }}$ cycle in $2 \mathrm{M} \mathrm{ZnSO}_{4}$ electrolyte. 

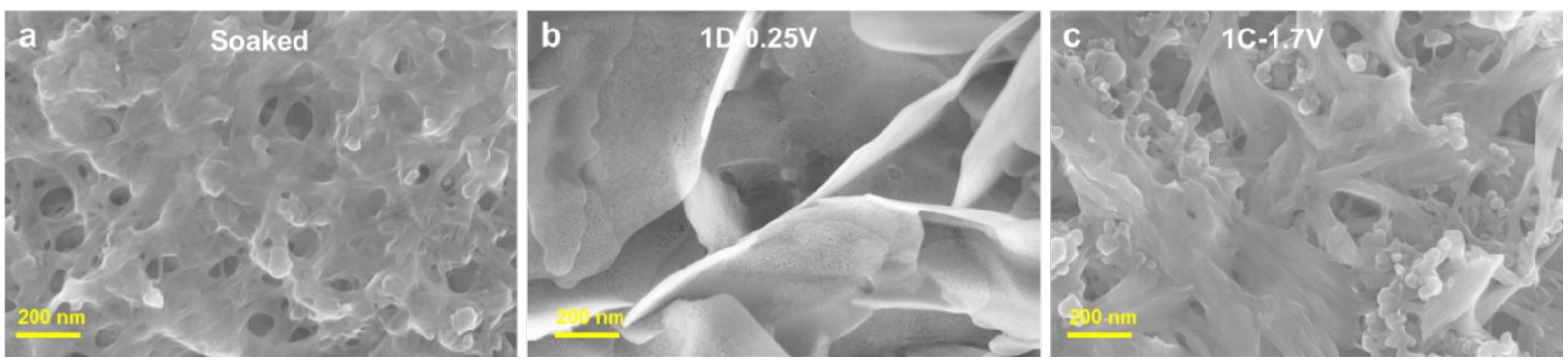

Figure S18 Ex-situ SEM images of the soaked $\alpha-\mathrm{V}_{2} \mathrm{O}_{5}$ cathode surface at the first cycle, pristine state (soaked), discharged state (1D-0.25V) and charged state (1C-1.7V) in $2 \mathrm{M} \mathrm{ZnSO}_{4}$ electrolyte, respectively.
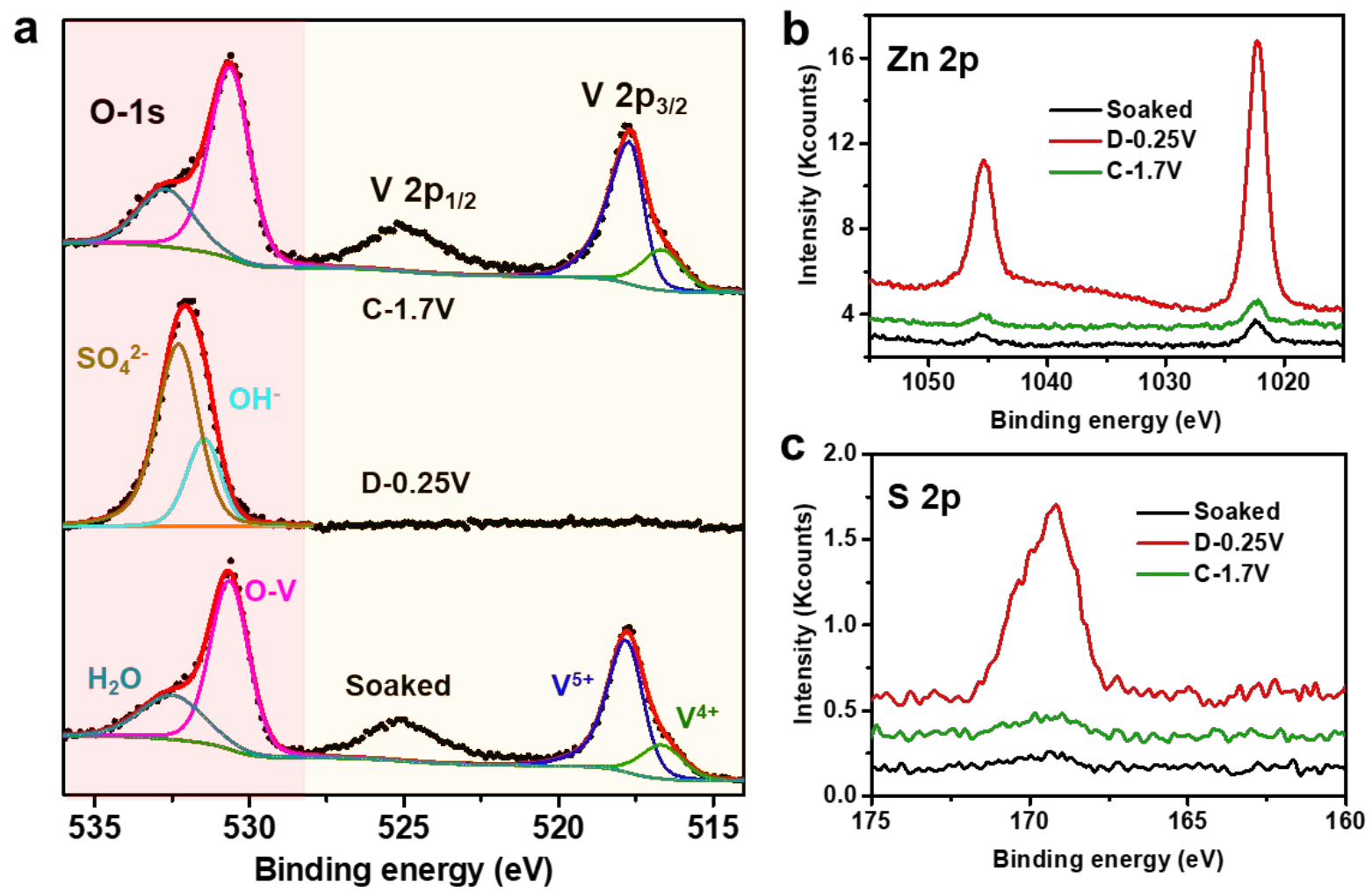

Figure S19 Ex-situ XPS spectra of (a) V-2p and O-1s, (b) Zn-2p, and (c) S-2p of the soaked $\alpha$ $\mathrm{V}_{2} \mathrm{O}_{5}$ electrode for 20 days at the pristine state (Soaked), discharged state (D-0.25V) and charged state $(\mathrm{C}-1.7 \mathrm{~V})$ in $2 \mathrm{M} \mathrm{ZnSO}_{4}$ electrolyte, respectively. 

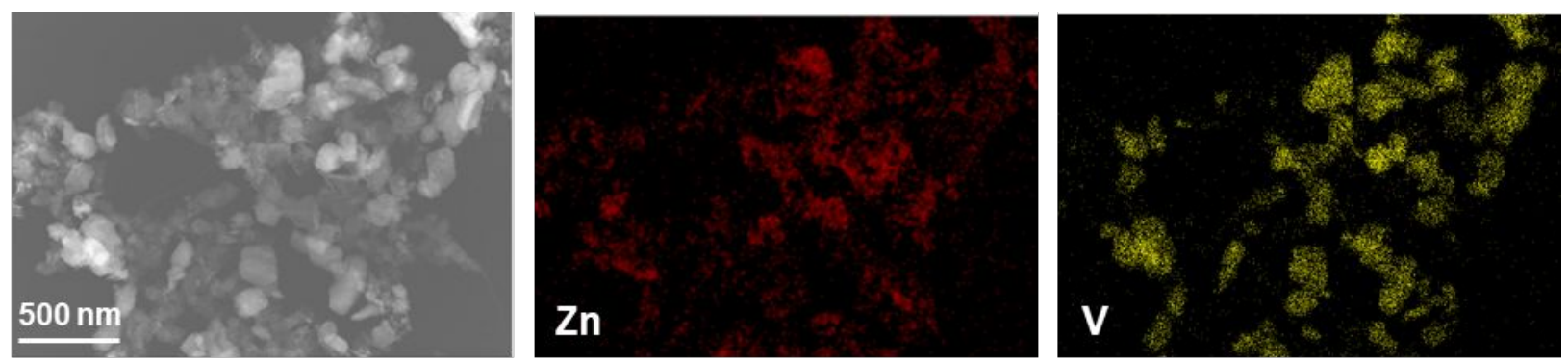

Figure S20 STEM image and Zn, and V mappings of $\alpha-\mathrm{V}_{2} \mathrm{O}_{5}$ particles at the discharged state (1D$0.25 \mathrm{~V}$ ) of the first cycle with a $2 \mathrm{M} \mathrm{ZnSO}_{4}$ electrolyte.

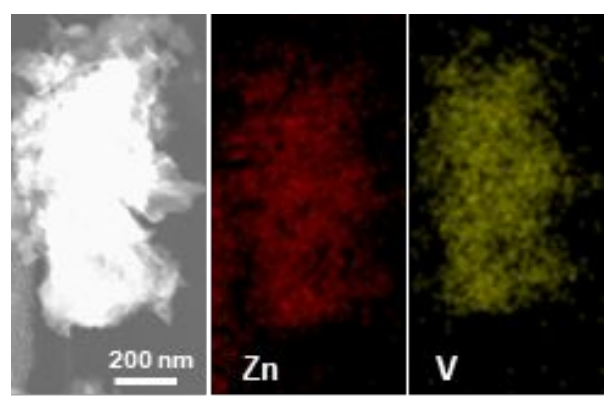

Figure S21 STEM image and $\mathrm{Zn}$, and V mappings of $\mathrm{H}-\mathrm{V}_{2} \mathrm{O}_{5}$ particles at the discharged state $(10 \mathrm{D}-0.25 \mathrm{~V})$ of the $10^{\text {th }}$ cycle with a $2 \mathrm{M} \mathrm{ZnSO}_{4}$ electrolyte. 


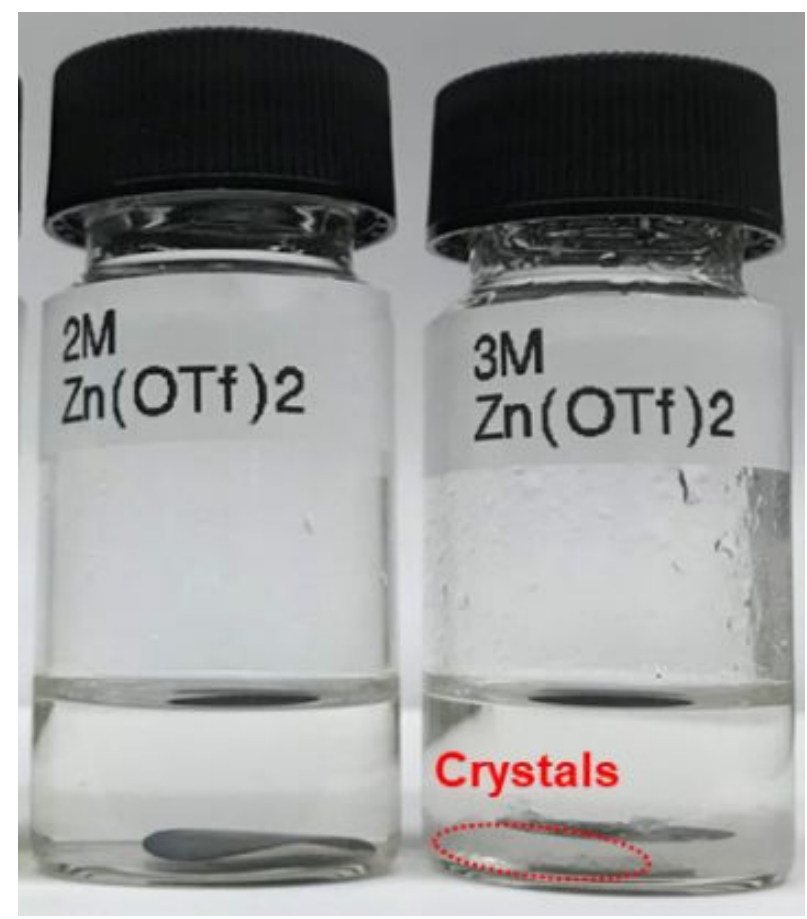

Figure S22 The optical image of $\alpha-\mathrm{V}_{2} \mathrm{O}_{5}$ in $2 \mathrm{M} \mathrm{Zn}\left(\mathrm{CF}_{3} \mathrm{SO}_{3}\right)_{2}$ and $3 \mathrm{M} \mathrm{Zn}\left(\mathrm{CF}_{3} \mathrm{SO}_{3}\right)_{2}$ solution (5 $\mathrm{mL)}$ after 1 day.
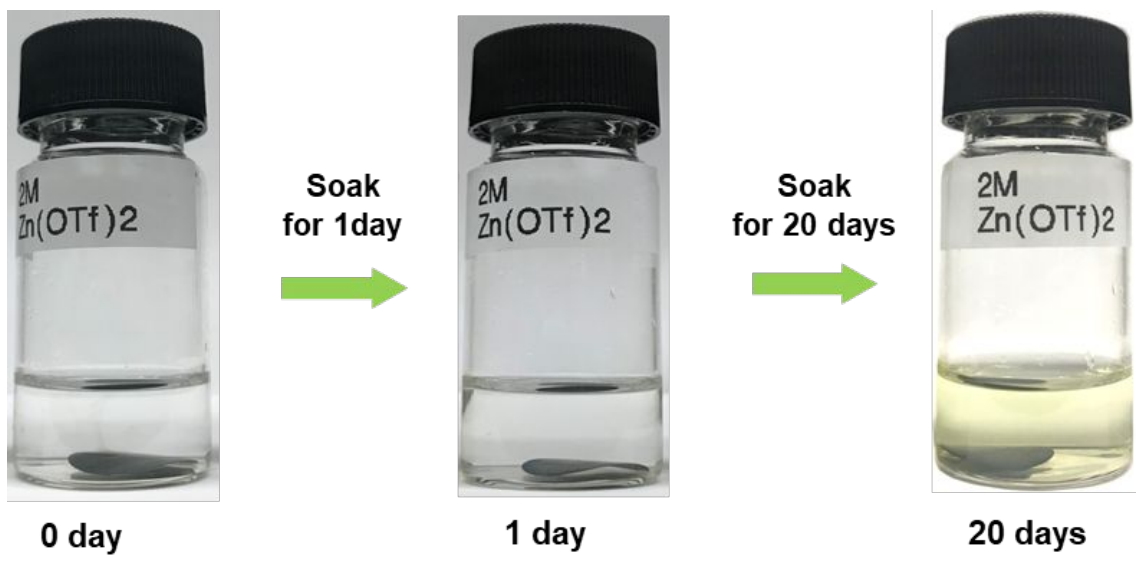

Figure S23 Digital images of the as-prepared $\alpha-\mathrm{V}_{2} \mathrm{O}_{5}$ electrode (active mass, $1.5 \mathrm{~g}$ ) soaked in 2 $\mathrm{M} \mathrm{Zn}(\mathrm{OTf})_{2}$ electrolyte $(5 \mathrm{~mL})$ for 0,1 and 20 days, respectively. 

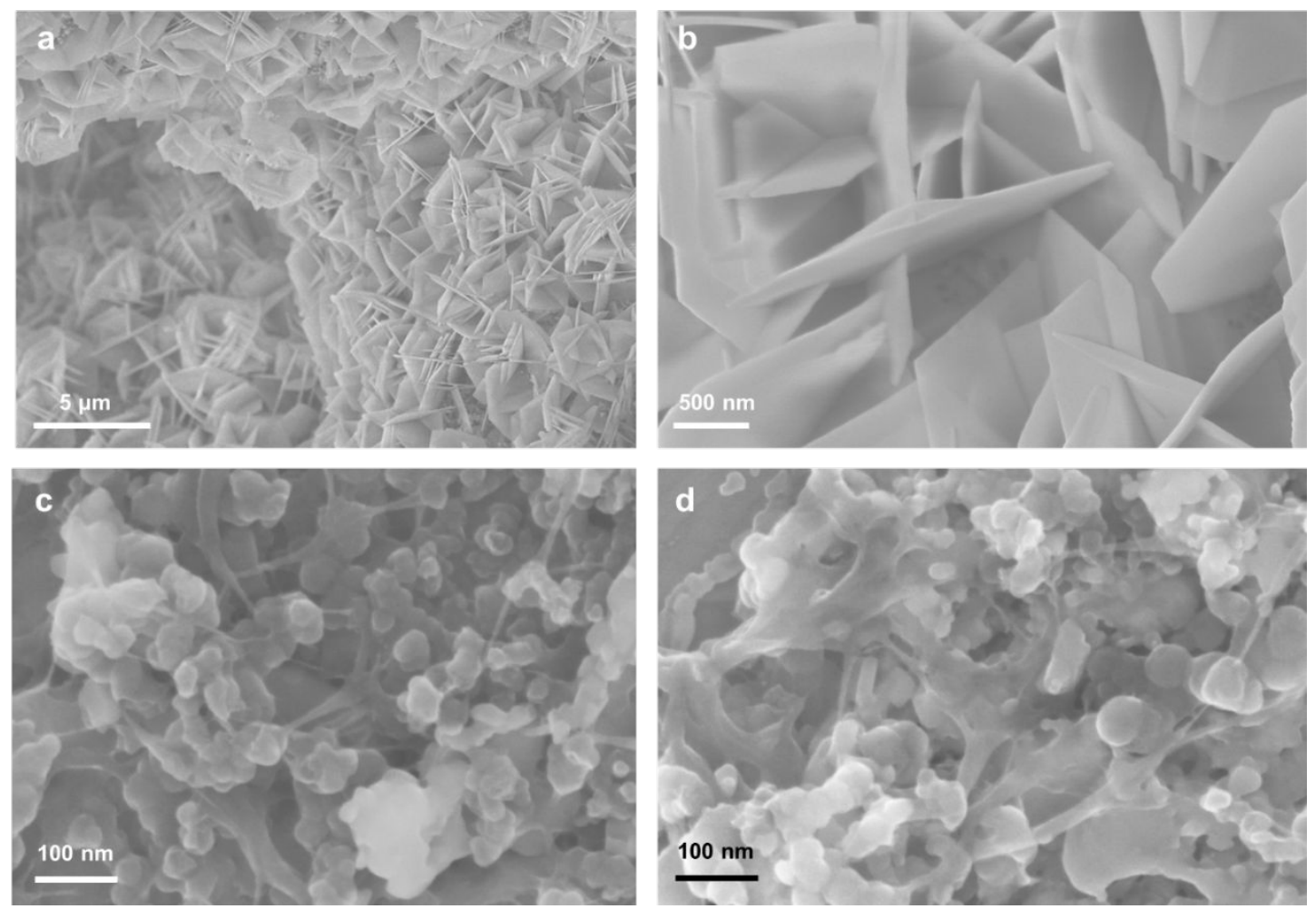

Figure S24 SEM images of $\mathrm{V}_{2} \mathrm{O}_{5}$ electrode after soaking in $2 \mathrm{M} \mathrm{Zn}(\mathrm{OTf})_{2}$ electrolyte $(5 \mathrm{~mL})$ for 20 days. (a, b) ZVO nanoflakes on the surface of electrode; (c, d) $\mathrm{H}-\mathrm{V}_{2} \mathrm{O}_{5}$ nanowires under the ZVO nanoflakes. 

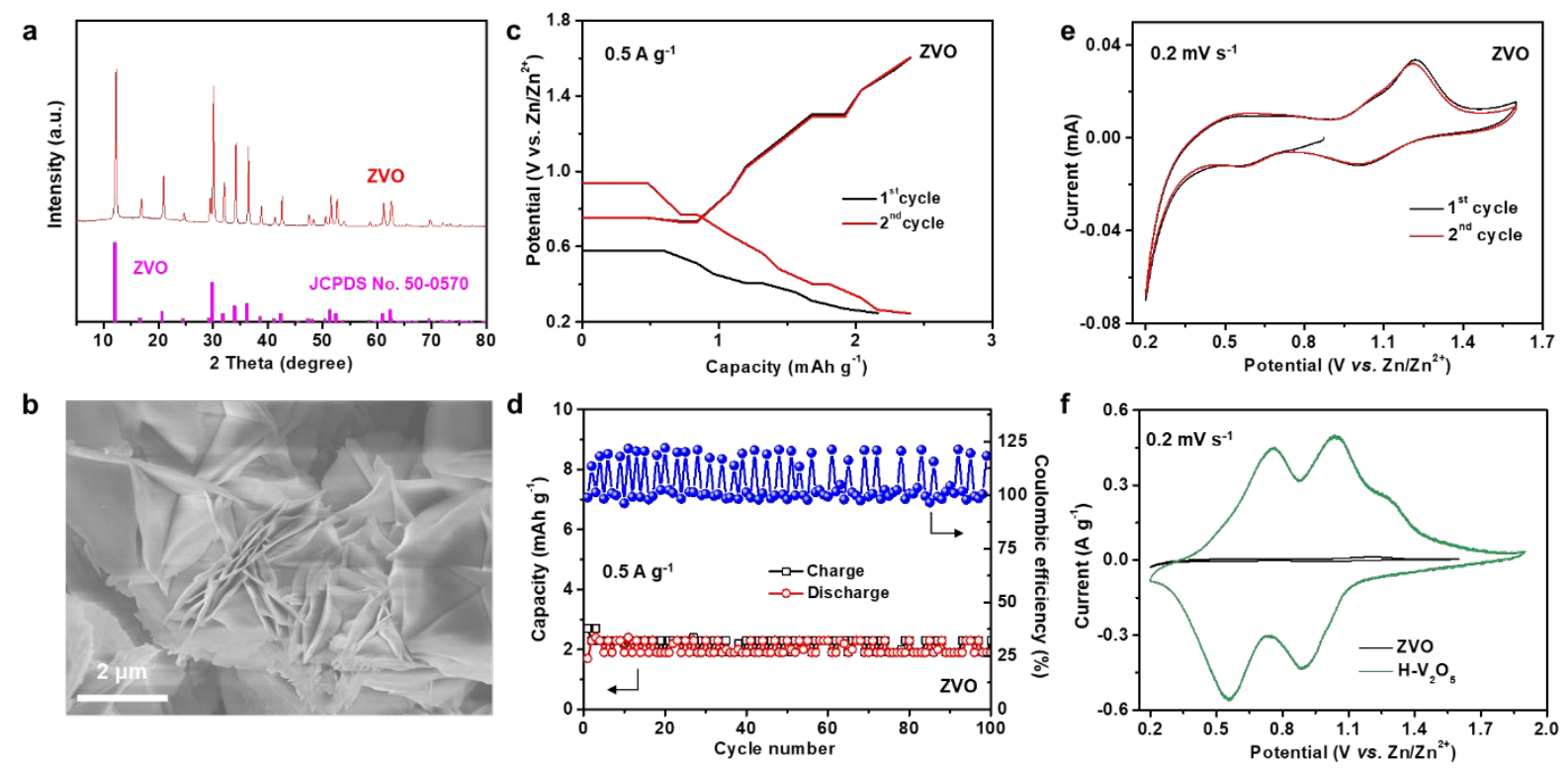

Figure S25 Structural and morphology characterization of the as-prepared ZVO powders: (a) XRD pattern; (b) SEM image. Performance of pure ZVO in ZIBs with $2 \mathrm{M} \mathrm{Zn}\left(\mathrm{CF}_{3} \mathrm{SO}_{3}\right)_{2}$ aqueous electrolyte: (c) discharge/charge profiles at first two cycles $\left(0.5 \mathrm{~A} \mathrm{~g}^{-1}\right)$; (d) long-term performance at $0.1 \mathrm{~A} \mathrm{~g} \mathrm{~g}^{-1}$; (e) $\mathrm{CV}$ current at $0.2 \mathrm{mV} \mathrm{s}^{-1}$; (f) $\mathrm{CV}$ comparison between $\mathrm{ZVO}$ and activated $\mathrm{VO}_{2}$ electrodes.

ZVO was prepared by a simple liquid phase precipitation method according to previous report. ${ }^{2}$ Briefly, $24 \mathrm{mmol} \mathrm{ZnSO}{ }_{4} \cdot 7 \mathrm{H}_{2} \mathrm{O}$ was dissolved in $240 \mathrm{~mL}$ deionized (DI) water to form a solution, denoted as solution A. $16 \mathrm{mmol} \mathrm{NH}_{4} \mathrm{VO}_{3}$ was dissolved in $160 \mathrm{~mL}$ DI water at $80^{\circ} \mathrm{C}$, denoted as solution B. After that, solution B was added into solution A to form a yellow suspension, and then stirred for $2 \mathrm{~h}$. The pale-yellow precipitates were collected by centrifugation and washed with DI water for 3 times. Finally, the final ZVO product was obtained after drying in vacuum at $60^{\circ} \mathrm{C}$ for $12 \mathrm{~h}$. 


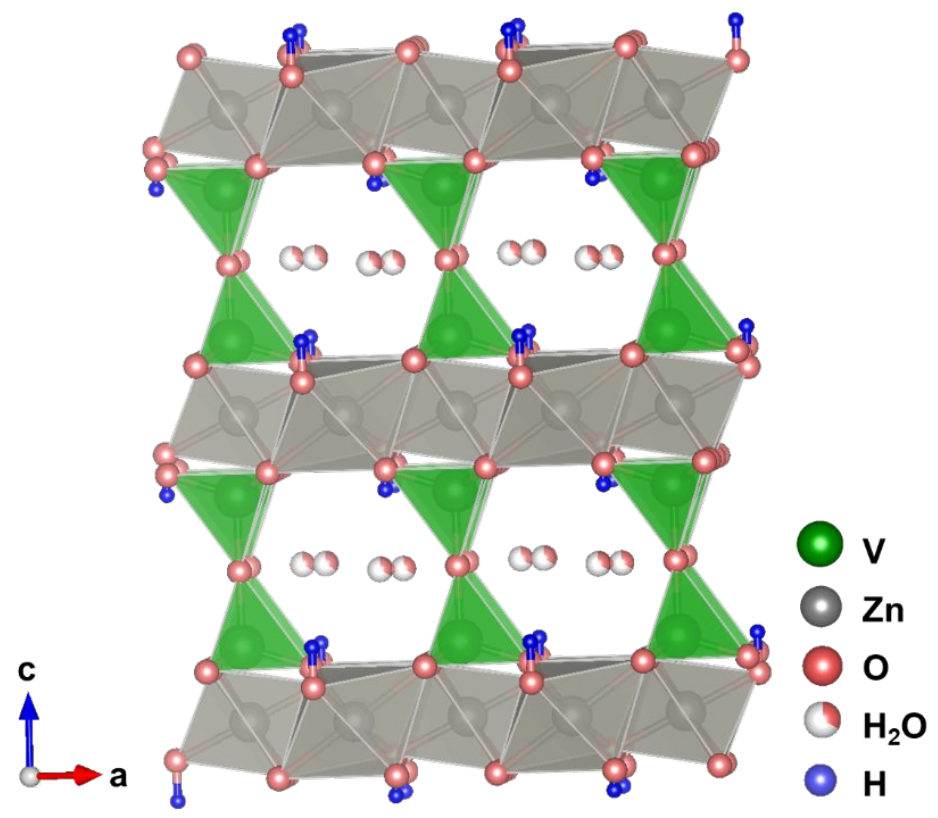

Figure S26 Crystal structure of $\mathrm{Zn}_{3}(\mathrm{OH})_{2} \mathrm{~V}_{2} \mathrm{O}_{7} \cdot 2 \mathrm{H}_{2} \mathrm{O}$.
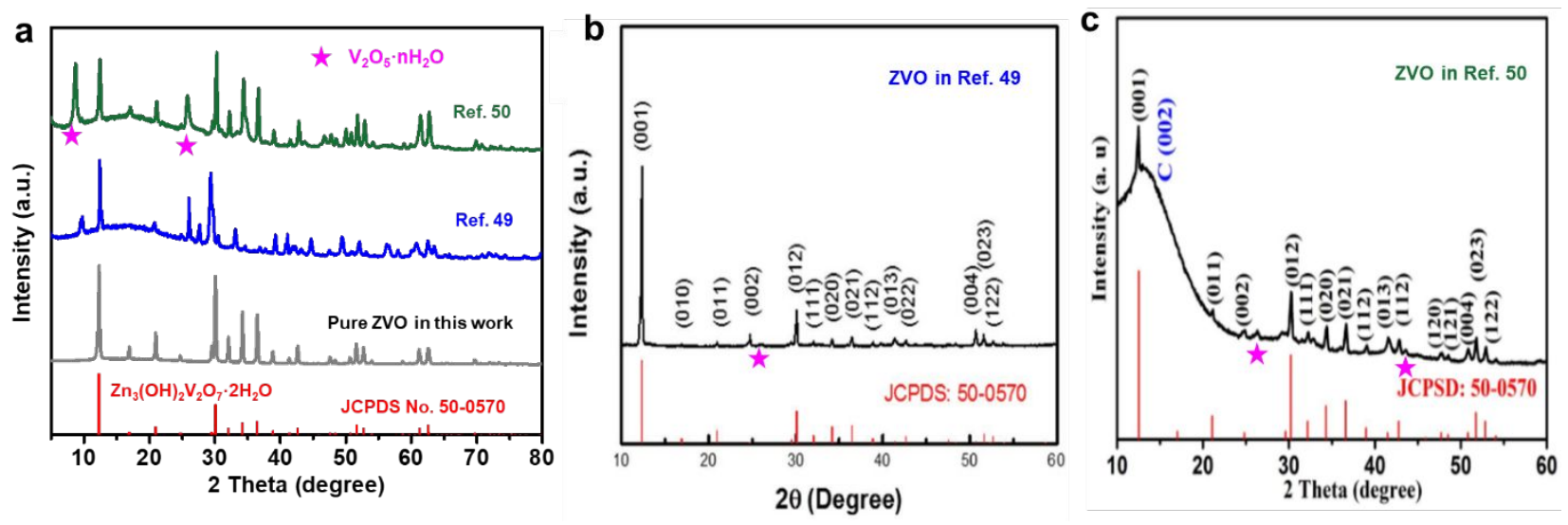

Figure S27 (a) XRD patterns comparison of pure ZVO prepared in this work and ZVO prepared using similar methods in ref. 49 and ref. 50. Apart from $Z \mathrm{VO}, \mathrm{V}_{2} \mathrm{O}_{5} \cdot \mathrm{H}_{2} \mathrm{O}$ will be generated using the synthesis method of ref. 49 and 50. XRD patterns of ZVO in (b) ref. 49 and (c) ref. 50. 


\section{References}

(1) Greenwood, N. N.; Earnshaw, A. Chemistry of Elements, Oxford: Pergamon Press 1984.

(2) Yan, H.; Luo, Y.; Xu, X.; He, L.; Tan, J.; Li, Z.; Hong, X.; He, P.; Mai, L. Facile and Scalable Synthesis of $\mathrm{Zn}_{3} \mathrm{~V}_{2} \mathrm{O}_{7}(\mathrm{OH})_{2} \cdot 2 \mathrm{H}_{2} \mathrm{O}$ Microflowers as a High-Performance Anode for Lithium-Ion Batteries ACS Appl. Mater. Interfaces 2017, 9, 27707. 